\title{
A preliminary assessment of professional footballers' awareness of injury prevention strategies
}

\author{
Richard D Hawkins, Colin W Fuller
}

\begin{abstract}
Players from five English professional football clubs completed a questionnaire containing 52 items relating to injury prevention practices and advice received on these issues. Responses were received from 55 players, which represents a mean response of 11 (4) and a response rate of 38 (14)\% from each club (means (SD)). The main deficiencies in awareness of injury prevention strategies for players were identified as: use of shin pads during training, carbohydrate intake before and after training and after matches, cool downs after training and matches, and flexibility work. These deficiencies indicate a need for wider education of players in current injury prevention strategies.

(Br f Sports Med 1998;32:140-143)
\end{abstract}

Keywords: football; injuries; attitudes; perceptions

During a prospective injury assessment project with professional footballers, it became apparent that many players were not implementing accepted control measures available for reducing the risk of injury. ${ }^{1} \mathrm{UK}$ health and safety legislation aims to protect employees, including professional sportspeople, ${ }^{2}$ from injury at work. Important aspects of this legislation are the requirements under Regulations 8 and 11 of the Management of Health and Safety at Work (MHSW) Regulations $1992^{3}$ for employers to ensure that employees have been provided with adequate information and training with regard to the hazards, risks, and control strategies related to their work. This study reports the findings of a limited survey to assess professional footballers' general awareness and application of injury prevention strategies.

Centre for Hazard and

Risk Management, Loughborough

University,

Loughborough, Leics

LE11 3TU, United

Kingdom

R D Hawkins

C W Fuller

Correspondence to: Dr C Fuller.

Accepted for publication 15 January 1998

\section{Methods}

Players from five English professional football clubs, who were taking part in a complementary injury assessment project, took part in a questionnaire based survey. The questionnaire was discussed with club physiotherapists before distribution to their professional playing staff for completion on a voluntary basis and return to the authors. Figure 1 is a copy of the questionnaire used in the survey.

In performing statistical analyses, Student's $t$ test for correlated means was used, and statistical significance was accepted at the $p<0.05$ level. Each value is reported as a mean (SD).

\section{Results}

Questionnaires were distributed to 146 professional players at five English League clubs, a mean club value of 29 (8). Fifty five players responded, which represents a mean club response of 11 (4) and a response rate to the questionnaire of $38(14) \%$. The player age and number of years as a professional footballer were 25 (4) years (range 18-38 years) and 6 (4) years (range 1-16 years) respectively. The players were from one Premier (9), two Division One (6 and 16), and two Division Two (9 and 15) teams, and their playing positions were as forwards (11), midfielders (24), defenders (14), and goalkeepers (6). The key findings from the survey can be summarised under the following headings.

\section{PROTECTIVE EQUIPMENT}

In competitive matches, 28 players always wore shin pads with additional ankle protection; however, 23 players never wore shin pads with ankle protection. In training, 51 players never wore shin pads of any type, even though 30 of these players agreed that wearing shin pads reduced the risk of lower leg injury. Fifty three players said that they were not encouraged by coaching staff to wear shin pads during training.

\section{NUTRITION}

While 43 players always consumed carbohydrates before a match, fewer than 20 players always consumed carbohydrates after a match or before and after training. This was despite the fact that players said that they were given some advice on the consumption of carbohydrates before (48) and after (40) matches, and before (40) and after (42) training.

\section{TRAINING}

Warm ups and cool downs

Forty nine players always warmed up before a match and before training; however, none of the players always cooled down after. While 51 players agreed/strongly agreed with the benefits of warming up with respect to the risk of injury, only 17 agreed with the benefits of cooling down. Thirty nine players gave reasons for not always cooling down after training or matches (table 1).

\section{Flexibility}

Fifty one players always stretched the major leg muscles before a match and before training but only two always stretched these muscles after. Forty players said they did not take part in any 
Table 1 Responses given by players for why cool downs are not always performed after training and matches

\begin{tabular}{lcc}
\hline Responses & Training & Match \\
\hline No time & 2 & 2 \\
Too tired & 19 & 20 \\
Not told to & 36 & 30 \\
No advice & 4 & 6 \\
Not necessary & 18 & 16 \\
Nobody else does it & 25 & 25 \\
\hline
\end{tabular}

team flexibility sessions, 36 did not perform individual flexibility work, and 29 players did not take part in flexibility sessions of any kind. Forty six players, who did not perform at least one flexibility session per week, gave responses to explain why. The reasons given were: "not told to do it" (26), "nobody else did it" (18), "did not believe it was necessary" (11), and "too tired" (4); no player responded that there was "not enough time". Only 24 players said they were "not given any advice on flexibility techniques" and 26 players agreed that "players with poor flexibility are more likely to get injured than those with good flexibility".

\section{FOOTBALL AND INJURIES}

\section{An assessment of professional footballers' awareness of injury prevention strategies.}

All questions are strictly confidential. Please be as truthful as possible and tick one box per question unless otherwise indicated.

PART A. 1. Age (yrs):

3. League: premier $\square \quad$ 1st $\square \quad$ 2nd $\square \quad 3$ rd $\square$

5. How many injurics have you received over the last $12 \mathrm{~m}$ i. competitive match injuries: $0 \square \quad 1$ 口 2 口 $30 \quad 4 \square \quad 5 \square>5 \square$ ii. training session injuries: $00 \quad 10 \quad 20 \quad 30 \quad 40 \quad 50 \quad>50$

PART B.

6. Do you wear shin-pads in training?

7. In competitive matches do you wear shin-pads with ankle protection?

$\begin{array}{ll}\text { always } & \text { very often } \\ (100 \%) & (-75 \%)\end{array}$

9. Do you have a warm-up period prior to:

$$
\text { i. training: }
$$$$
\text { ii. matches: }
$$

10. Do you have a cool-down period at the completion of: i. training:

ii. matches:

11. Do you stretch the major leg muscles in the following situations?

$i$ warming-up prior to training:

i. warming-up prior to matches.

iii. cooling-down after training:

iv. cooling-down after matches:

12. Do you undertake flexibility training (not included as part of a warm-up or cool-down)?

times per week as part of a team session:

ii. times per week as extra individual work:

13. Do you undertake strength training in the gym?

i. tines per week as part of a team session:

ii. times per week as extra individual work: $\square$
$\square$
$\square$
$\square$

1 므

10
10
2. Number of years as a professional:

4. Playing position: goalkeeper $\square$

defender $\square$ midfielder $\square$ forward $\square$

$\square$
$\square$

$\square$
$\square$
$\square$

often

$(-50 \%)$

$\square$

口

$\square$

$\square$

$\square$

$\square$

$\square$

ㅇㅁㅁ

$\because 0$ $\square$

0
0
0
0

$\square$

品

문 $\square$
$\square$
$\square$
$\square$

$\square$

ם

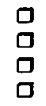

$\begin{array}{cc}\begin{array}{l}\text { sometimes } \\ (-25 \%)\end{array} & \begin{array}{l}\text { never } \\ (0 \%)\end{array} \\ \square & \square \\ \square & \square \\ & \\ \square & \square \\ \square & \square \\ \square & \square \\ \square & \square \\ \square & \square \\ \square & \square \\ \square & \square\end{array}$

PART C. In the following questions tick the description which most closely matches your opinion of the statement.

14. The chance of sustaining an injury during training that prevents you from being available for selection is likely.

15. The chance of sustaining an injury during a competitive match that prevents you from being available for selection is likely.

16. There is a greater chance of sustaining an injury during a competitive match than during training.

17. Injuries are a consequence of the actions of other players.

18. The risk of lowcr-leg injuries in training is reduced by wearing shin-pads. strongly agree

agree

neither agree nor disagree disagree

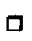

$\square$

$\square$

$\square$

$\square$ $\square$
$\square$
$\square$

$\square$
$\square$
$\square$
$\square$

$\begin{array}{ll}3 \square & >3 \square \\ 3 \square & >3 \square\end{array}$

$\begin{array}{ll}3 \square & >3 \square \\ 3 \square & >3 \square\end{array}$ 

strongly agree agree $\quad \begin{aligned} & \text { neither agree } \\ & \text { nor disagree }\end{aligned} \quad$ disagree $\quad$ strongly disagrce

19. Injury is more likely towards the end of a match.

$\square$

$\square$

$\square$

$\square$

20. The risk of injury is reduced by thoroughly warming-up and stretching prior to:

i. training:

ii. matches:

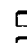

a

$\square$

21. The risk of injury is reduced by thoroughly cooling-down and stretching after:

i. training:

ii. matches:

a

$\begin{array}{lllll}a & a & a & a \\ 0 & a & a & a\end{array}$

22. Players with poor flexibility are more likely to get injured than those with good flexibility.

$\square$

23. Strong muscles are important in the protection against injury.

口

$\square$

$\square$

The majority of other players wear shin-pads Juring

training.

$\square$

$\square$

$\square$

$\square$

PART D.

25. If you do not undertake the following activities indicate all the reasons why not. - strength training at least once per week $\quad$ - warm-ups always before training and matches -flexibility training at least once per week - cool-downs always after training and matches

\begin{tabular}{|c|c|c|c|c|c|c|}
\hline \multirow[b]{2}{*}{$n / a$} & \multirow{2}{*}{$\begin{array}{l}\text { strength } \\
\text { training } \\
\square\end{array}$} & \multirow{2}{*}{$\begin{array}{l}\text { flexibility } \\
\text { training } \\
\square\end{array}$} & \multicolumn{2}{|c|}{ warm-ups } & \multicolumn{2}{|c|}{ cool-downs } \\
\hline & & & $\begin{array}{c}\text { training } \\
\square\end{array}$ & $\begin{array}{c}\text { matches } \\
\square\end{array}$ & $\begin{array}{l}\text { training } \\
\square\end{array}$ & $\begin{array}{c}\text { matches } \\
\square\end{array}$ \\
\hline $\begin{array}{l}\text { a. not enough time } \\
\text { b. too tired after training/matches } \\
\text { c. are not told to do it } \\
\text { d. are not given advice on techniques } \\
\text { e. do not believe it is necessary } \\
\text { f. nobody else does it }\end{array}$ & $\begin{array}{l}\square \\
\square \\
\square \\
\square \\
\square \\
\square\end{array}$ & $\begin{array}{l}\square \\
\square \\
\square \\
\square \\
\square \\
\square\end{array}$ & $\begin{array}{l}0 \\
\square \\
0 \\
0 \\
0 \\
0\end{array}$ & $\begin{array}{l}\square \\
\square \\
\square \\
\square \\
\square \\
\square\end{array}$ & $\begin{array}{l}\square \\
\square \\
\square \\
\square \\
\square \\
\square\end{array}$ & $\begin{array}{l}\square \\
\square \\
\square \\
\square \\
\square \\
\square\end{array}$ \\
\hline
\end{tabular}

26. Are you encouraged to wear shin-pads during training?

yes $\square$

no $\square$

27. Are you given any nutritional advice on what to eat:

i. before training:

ii. after training:

iii. before matches:

iv. after matches:

$\begin{array}{lll}\text { a lot } \square & \text { a little } \square & \text { none } \square \\ \text { a lot } \square & \text { a little } \square & \text { none } \square \\ \text { a lot } \square & \text { a little } \square & \text { none } \square \\ \text { a lot } \square & \text { a little } \square & \text { none } \square\end{array}$

28. Rank the following injury mechanisms from 1-10, and injury locations from 1-11, for both the likelihood of receiving an injury and severity of injury separately, 1 being the most likely and the most severe.
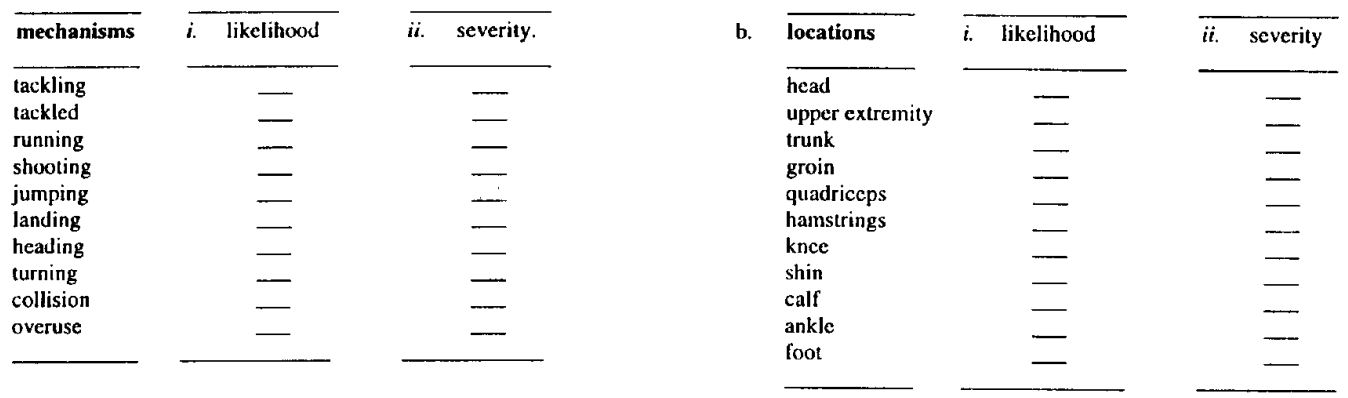

29. Have you any other comments concerning football and injuries that you would like to bring to our attention.

Figure 1 Questionnaire designed to assess professional footballers' awareness of injury prevention strategies.

Strength

Thirteen players said they did not take part in any team strength sessions, and eight did not perform individual strength work. Thirty six players took part in one or two strength sessions per week as a team, and 39 performed extra individual work; only three players reported that they did no strength work. Forty six players agreed with the statement that "strong muscles are important in the protection against injury".

\section{Discussion}

While the present study only assesses the responses from a limited number of players in 
five football clubs, the results do indicate deficiencies in players' knowledge and implementation of injury reduction measures. The main deficiencies identified relate to an appreciation of the benefits of the use of shin pads during training, carbohydrate intake before and after training and after matches, cool downs after training and matches, and flexibility work. These preliminary results indicate that football clubs are not meeting the legal requirement under Regulations 8 and 11 of the MHSW Regulations $^{3}$ of providing adequate infor- mation and training on injury prevention strategies. The results of this study indicate the need for a comprehensive assessment to determine whether these results are representative of the majority of professional footballers.

1 Bangsbo J. Fitness training in football: a scientific approach. Bagsvaerd: HO+Storm, 1994.

2 Fuller C W. Implications of health and safety legislation for the professional sportsperson. Br f Sports Med 1995;29:59.

3 Management of Health and Safety at Work Regulations 1992. London: HMSO, 1992. (SI 1992, No 2051).

\section{Footballer's ankle}

There is no doubt that articular cartilage requires a certain amount of movement for it to remain healthy. On the other hand, excessive and abnormal movement is unhealthy for it and will inevitably lead to degenerative change.

The term "footballer's ankle" was coined by T P McMurray ${ }^{1}$ of Liverpool. In an article published posthumously in 1950 he described case histories of three professional footballers who had ankle problems. He also mentioned that he had treated three other footballers in this short anecdotal paper. $\mathrm{He}$ described how in football the foot is usually in a position of full equinus when kicking the ball. This leads to strain on the anterior capsule of the ankle joint. He suggested that this eventually gave rise to a bony outgrowth into the capsule of the joint from the anterior margin of the tibia, or from the neck of the talus. He pointed out that, although the appearance of osteophyte formation suggested arthritic change in the ankle, the articular surfaces were normal. All his patients were cured by an open operation to remove bone from the capsule of the ankle joint.

Scranton and $\mathrm{McDermott}^{2}$ subsequently described the same condition as "anterior tibiotalar spurs". They classified these lesions into four categories, in which type IV included arthritic change. Their paper from Seattle described this condition in 37 patients. Their series included American footballers and baseball players, as well as ballet dancers. They compared the results of open excision of the spur with the results of arthroscopic excision. It is clear that the spur is not in the capsule of the ankle joint, but arises within the joint at the articular surface of the tibia. In their series, the follow up of the arthroscopy group was quite short. Success was judged by subjective criteria-that is, when the patient felt that the ankle was better than before the operation and was able to return to unlimited athletic activity. By this criterion all patients in both groups had good results. The patients in groups I and II appeared to recover more quickly than those in groups III and IV.
A recent prospective study by van Dijk and colleagues from Amsterdam has given further results of arthroscopic surgery. ${ }^{3}$ Out of 62 patients, his series included 24 soccer players. This paper gives useful technical hints on the removal of osteophytes arthroscopically. This was achieved using either a small osteotome or an arthroscopic shaver. They confirm that the osteophytes are actually within the joint and not within the capsule of the joint. It is not surprising that the ankle is injured by kicking a football, as the average kicking velocity is given as $96 \mathrm{~km} / \mathrm{h}$. During a match there would be 60-120 such contacts for each player, and the ensuing microtrauma in a position of dorsiflexion must be the reason why such lesions are common in professional footballers.

The results of arthroscopic excision of osteophytes for ankle impingement are certainly encouraging. Patients with smaller osteophytes seem to do better. My own experience of professional footballers with Scranton-McDermott type I and II lesions has been excellent. After arthroscopic excision of osteophytes, even those larger than 3 $\mathrm{mm}$ in size (grade II), a good recovery may be expected within weeks of the operation. With intensive physiotherapy, most professional footballers are able to play again four to six weeks after this type of arthroscopic procedure.

The long term outcome is not known. Undoubtedly, former professional footballers may develop severe osteoarthritis of the ankle. Although excision of osteophytes gives good short term results, there is no evidence that it will prevent long term degenerative change in the ankle joint.

Consultant Orthopaedic Surgeon

T W D SMITH

Northern General Hospital

Sheffield

1 McMurray TP. Footballer's ankle. $\mathcal{F}$ Bone foint Surg $[\mathrm{Br}]$ 1950;32:68-9.

2 Scranton PE Jr, McDermott JE. Anterior tibiotalar spurs: a comparison of open versus arthroscopic debridement. Foot Ankle 1992;13:125-9.

3 van Dijk CN, Tol JL, Verheyen CCPM. A prospective study of prognostic factors concerning the outcome of arthroscopic surgery for anterior ankle impingement. $\mathrm{Am}$ $\mathfrak{f}$ Sports Med 1997;25:737-45. 